\title{
Occupational Health Services and the Socialization of the post-Fordist Employee
}

\section{Christian Maravelias}

School of Business

Stockholm University

Email: chm@fek.su.se

\begin{abstract}
There is a heightened interest in the health of employees among scholars, employers, legislators, and employees themselves. The concern for employees' health is not a new phenomenon. It has held a central position in political and economic discourses throughout most of the twentieth century. The central argument of this article, however, is that the economic and political changes of the last three decades - the neo-liberal turn - have played a part in altering the very notion of health so that the healthy individual is now a person who not merely passes bio-medical tests, but a person who also leads a particular life and possesses particular skills, namely, those of the active, positive, and self-governing individual. By means of a qualitative study of the sector for occupational health services (OHSs) in Sweden, this article will show how an active lifestyle has become a defining criterion of health. Furthermore, it will describe how health thereby becomes a question of choice and responsibility and how the healthy employee comes across as morally superior to the unhealthy employee. In this connection, this article shows how health experts such as therapists, health coaches, physicians, and so on become important points of authority in the fashioning of the new healthy, active employee.
\end{abstract}

Keywords: self-governing, health promotion, medicalization, post-Fordism

\section{Introduction}

This article examines the role that occupational health services play in ensuring that employees willingly and capably adapt to the requirements of current capitalist labour processes. It is widely accepted in social as well as in economic theory that a capitalist system relies on its abilities to subordinate and control living labour according to the principles of capitalist production and 
consumption (Agglietta, 1979; Harvey, 2006). This obviously involves a multitude of different activities - education, the mobilization of social sentiments such as loyalty and professional pride, emotional identifications created via the media and more - and out of these the measures directly and indirectly taken in the names of individuals' health constitute but a small part. Nevertheless, health measures are important to study because they tend to concern much broader issues than those of maintaining a working population fit for work in a strict, clinical sense. More specifically, over and above that of securing individuals' physical and psychological fitness for work, measures taken in the name of the health of employees tend to play a part in the socialization of employees who lead lives which correspond to moral criteria of what is considered 'a good life' and 'a good employable man' (Crawford, 2006). It is the function of health measures and health expertise in relation to the management of employees who willingly subordinate their lives and themselves to the principles of the current regime of capitalist accumulation that is the focus of this article.

This article contains three parts. Below I present the well-known distinction between Fordism and post-Fordism with a specific interest in how health issues and health expertise have played a part in fashioning the ideals, norms, and practices that make up the employable individual. This section is then followed by a case study that illuminates current developments in the sector for occupational health services (OHSs) in Sweden. This article ends with a discussion and conclusions.

\section{Fordism - the factory regime}

In the early twentieth century persons as different from each other as the Swedish social-democratic intellectuals Alva Myrdal and Gunnar Myrdal (1997), the imprisoned Italian Marxist intellectual Antonio Gramsci (1996), and the American industrialist Henry Ford all identified the quality of the working population as a core problem for western industrializing societies. By 'quality of the working population', they meant not just individuals' strict professional competencies, but also their general cultural capacity to live and function in accordance with the principles of mass production and mass consumption implied by the developing factory regime. Ford realized already in the 1910s that his employees were ill-adapted to a life as a worker in his factories. As his workers did not eat properly, drank too much alcohol, consumed irrationally, and did not put aside enough savings, he sent doctors out as social workers to the homes of his workers for the sake of teaching them the 'proper ways of life' (Harvey, 1991). Foreseeing that this problem would require far more than the individual efforts of industrialists like Ford, Gramsci (1996) claimed in the 1930s in his Prison Notebooks that industrialization would result in 'the biggest collective effort to date to create, with unprecedented speed, and with consciousness of purpose unmatched in history, a new type of worker and a new type of man'. This was, of course, a highly intricate and politically sensitive affair. How would this creation 'of a new worker and a new man' be achieved? Furthermore, how would it be achieved so that both the capitalist class and the working class would accept it? It was precisely as an answer to both these questions, that is, to both the economic and the political dimensions of the issue about the quality of the working population, that Myrdal and Myrdal (1997) developed their notion of a welfare state. To the extent the factories were to become efficient and accepted engines of the newly industrialized societies, welfare systems, predominately public health 
along with childcare and public schools, were required to socialize and maintain a population that were both willing and able to the adhere to the norms underlying the Fordist society: discipline with regard to daily routines at work and in private life, obedience with regard to those with authority in the factories and in society at large, and loyalty with regard to the collective task of building the welfare state.

Foucault's works on discipline and power perhaps best describe the principles of how the socialization of individuals' was achieved (e.g., 2007). In his view, this socialization was done through a welfare state that used neither force nor domination, but instead set up specialized institutions governed by experts (in medicine, psychology, economy, etc.) who made sure that their 'scientific' observations and judgements gradually became part of individuals' own understandings of who they were and how they ought to behave (Dean, 1999; Rose, 2007). Within this system of 'knowledge/power', Myrdal and Myrdal have emphasized the importance of health expertise, noting that: 'already during their university studies medical doctors must be equipped with the social-hygienic insights for sanitary inspections and control ... especially housing inspections' (1997, 248, my translation). In factories, schools, and families 'medical doctors and nurses are required as authorities who lead and supervise', but, above all, who 'enlighten and discipline' (1997, 248, my translation) for the sake of maintaining a sufficiently large population of individuals who are not merely clinically healthy and hygienic, but also appropriately socialized for the new Fordist society. The good and employable man is a healthy man; and a healthy man is a man who maintains strict daily discipline in alignment with the norms endorsed by those in authority.

\section{Post-Fordism - the flexibility regime}

The alliance between the factory regime and 'Welfarism' - that is, Fordism achieved almost three decades of steady growth. ${ }^{1}$ Yet around 1970 increasing intercontinental competition pushed the US and the world into an economic crisis. Two general reactions to the crisis among capitalist firms would prove to undermine gradually the Fordist political economy. On the one hand, firms reduced the quantitative need for workers, and, on the other hand, they altered the type or qualities of workers required. More specifically, shrinking demands and profit margins led capitalist corporations to try to cut down labour costs either by extensive technological automation or by relocating factory production to low-wage countries in South-East Asia, South America, and later China (Arrighi, 1994). This development permanently raised the level of

\footnotetext{
${ }^{1}$ In part this growth was due to how Fordism managed immediately to curb social and political unrest by providing social security to the lower and middle working classes (unemployment support, public schools and health care, etc.), and, in that very process, was able to socialize a working population appropriately configured for mass production and mass consumption. Yet this growth was also in part due to the fact that the Second World War had torn most of Europe's and Japan's production facilities apart while leaving the US intact. The war thus temporarily 'solved' the capitalist economy's inescapable need for growth; not only could the US profitably invest its excess capital in Europe and Japan, it could also through these investments establish for itself a market where it could profitably sell the commodities it could not sell in its home market. Eventually, however, European (especially German) and Japanese production facilities were rebuilt, and these countries began to look to the US to find markets where it could both invest its excess capital and export its excess commodities.
} 
unemployment, and in turn made it increasingly difficult to find support for costly, taxed-based welfare systems both from big capital and from the middle and upper classes. As Bourdieu (1999) and Bauman (1998) have noted, the welfare state was strongly supported by these groups and classes as long as the growth of the economy was based on the welfare state's securing a corresponding growth of an appropriately configured army of submissive workers; when profits no longer came from getting workers into the factories and began instead to be derived from getting them out (so called 'down seizing'), the welfare state began to be seen as a system where those who are valuable support an underclass of people who are not.

Yet the persistence of higher levels of unemployment was not the only problem that undermined the legitimacy of the welfare state. The welfare state also began to be seen as a problem in itself; by taking over the responsibility for the populations' health, education, employability, and so on, it was seen to create a passive and dependent working population that was unfit to handle the requirements of reformed and more competitive labour markets. This critique was related to another reaction to the economic crisis among capitalist corporations, that is, to attempts to establish new more flexible and innovative organizational arrangements that would make them better able to exploit emerging markets. As Smith (1997) points out, this 'flexibilization' involved two dimensions, which were both based on the distinction between core and noncore activities: on the one hand, a 'numerical flexibility' was achieved by giving non-core workers temporary employment contracts so that they could quickly be laid off. ${ }^{2}$ On the other hand, a 'functional flexibility' was achieved via modes of organization such as team work, project work, through an emphasis of corporate culture instead of rules and so on, all of which attempted to tie and commit the core employees closer to their organizations (e.g., Smith, 1997; Vallas, 1999). While core employees would work harder, longer, more creatively, and more enthusiastically because they were committed to their work and their organization, peripheral employees would do so because they were afraid of losing their jobs.

It is important to note that regardless if workers were part of the core or the periphery, the new regime of flexibility required a new type of individual who was active and self-governing rather than passive and submissive. In this way this regime reopened the issue about the 'quality of the working population'. The welfare state had been effective in socializing individuals who accepted a limited freedom of choice in work as well as in consumption and life, who skilfully followed routines, and who developed a specific work-based identity through a stable and unbroken career. In a situation where stable jobs and uninterrupted careers became increasingly rare and sometimes were replaced by temporary jobs, blurred boundaries between previously distinct occupations, patch-work careers, and the like, it was no longer the 'organization man' (Whyte, 2002) who the welfare state so effectively had been part of 'prefiguring' but the innovative entrepreneur, namely, the person capable of seizing on fleeting opportunities, who was now idealized.

\footnotetext{
2 The pursuit of numerical flexibility has involved a move away from regular employment towards temporary employment. Furthermore, it has concerned tasks and activities which have been defined as peripheral in relation to a corporation's core activities and tasks. As a result, the number of flexible employees who can be taken onboard quickly and who can be let go with little economic and political cost when there is less need for them has increased steadily in both Europe and the US since the 1970s (Evans et al., 2004; Smith, 1997; Vallas, 1999).
} 
It is in relation to this reopened issue about the quality of the working population that programmes in Worksite Health Promotion (WHP) emerge as new ways of socializing employees who are capable and willing to manage themselves in accordance with contemporary ideals and practices of flexibility, self-discipline, and self-improvement at work as well as in private life. As will be shown below, while WHP is still an example of the knowledge-based forms power that reached their apogee during the Fordist era, it also differs in some significant ways that makes it illustrative of a typical post-Fordist form of power (cf. Rose, 2007; Dean, 1999). As we shall see, the form of power exercised through WHP operates not primarily through health experts employed by the State, but through health experts selling their services via the market. This characteristic, furthermore, plays an important role in transforming the health expert from that of a 'detached' observer who disciplines employees' conduct to that of an involved coach or mentor who listens to the employee and morally guides him or her towards self-discipline and self-improvement (Rose, 2007).

Yet, as will be indicated, WHP also plays a role in handling the other central issue in post-Fordist societies mentioned above, namely, what society should do with the increasing amount of people who are excluded from the labour market. Here WHP appears to provide ways of sorting out those who are unfit for work either on moral grounds (your ill health is a result of the lifestyle you yourself have chosen) or on medical grounds (your unemployment is a result of your illness or disability).

\section{Empirical material}

The basic aim of the study of the sector for occupational health services (OHSs) in Sweden was to understand better how these services relate to human-resource management (HRM) programmes and activities within its client companies. More specifically, to the extent that contemporary HRM practices increasingly seek to make use of 'the whole' individual by attempting to foster particular individuals that freely subordinate themselves to corporate values (Barrat, 2002, Covaleski et al., 1998), the ambition was to study which role occupational health services and health experts play in this pursuit. The material presented below comes from a study of the Swedish sector for OHSs that was conducted in two stages, first between 2004 and 2006 and secondly between 2007 and 2009. Forty-five in-depth interviews were conducted with three separate groups of interviewees: (1) professional and administrative staff from seven different organizations within the sector for OHSs; (2) humanresource (HR) managers and line-managers working for firms which are customers to the OHSs companies; (3) employees who had taken part in some kind of health-promotion programme or service. Twenty-five of the interviews were held with people from the first group, nine with people from the second, and nine with people from the third group. Human-resource managers, line managers, as well as employees who had taken part in some health-promotion programme were contacted in client companies to the selected OHSs companies. The selection of companies in the OHSs sector as well as client companies was based mainly on access. Interviews were semistructured; participants were asked to describe their professional role, how they found their professional role to have changed, which main problems and issues they dealt with, and which concrete methods they used. All interviews were held in Swedish. The quotations below are translations from Swedish. 


\section{OHSs - general background}

Most countries in the developed world have laws stipulating that employers should employ OHSs when required. These laws are mostly based on the International Labour Organization's (ILO) Occupational Health Service Convention in 1985. This convention defines OHSs as

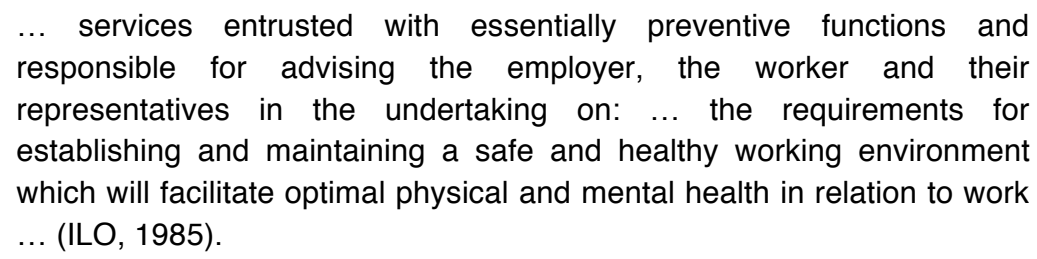

The convention, furthermore, specifies the overarching functions of OHSs as the identification and assessment of health risks, the provision of advice on how to organize work in order to minimize health risks, and the surveillance of workers' health in relation to work (see also SOU, 2004: 113). The convention does not give directives as to how OHSs should be financed or organized. Yet most countries have adopted one of the following three models: OHSs which are state-funded or subsidized via taxation; OHSs which are sold on a market by OHSs companies in competition with other OHSs companies; and OHSs which are set up, used, and financed by a group of companies as a joint venture. The models are not mutually exclusive. OHSs can be subsidized by the state, but they can still be organized via the market, or can basically be market-financed, but organized as a joint venture, and so on. Apart from the US, which never really adopted the European notion of the welfare state and where OHSs accordingly have mainly been market-financed all along, countries in Europe and Australia have mainly gone from a system where OHSs were part of the state-funded or subsidized welfare arrangements to a neo-liberalized system where OHSs are largely market-financed. Finland is a somewhat rare example of a country that has held on to a state-funded OHSs system, whereas the Netherlands and Sweden are more typical examples of countries that have adopted a largely market-financed OHSs system (SOU, 2011: 79).

\section{Worksite Health Promotion in the Swedish sector for occupational health services}

In Sweden cooperative agreements between unions and employer organizations have traditionally regulated OHSs and the Swedish state subsidized 50 per cent of the costs. In the mid-1990s state funding was terminated and the OHSs sector became market-financed. This had a number of significant 'contractual implications' (Donzelot, 1991) with regard to effects on organizational, individual, and professional identities, and on professional relations. In particular, the new contractual mechanisms resulted in suppliercustomer relations replacing the cooperative agreements, whereby OHSs companies were driven to establish relations with and to win the loyalty of employer representatives - which now became their customers. In that process the type of clients and customers as well as the type of health services offered shifted. Previously, OHSs had primarily been directed towards the quantitatively largest groups of employees in the working population and the services mainly concerned the prevention and rehabilitation of work- 
related injuries or illnesses. As a head of customer relations in an OHSs company explained, the situation is now different:

$[\mathrm{T}]$ he leading OHSs companies seek to get away from working with the prevention of illness and injuries. I mean, heavy-labour, intense industries, where a significant part of the preventive health measures used to be directed, either have been automated throughout or have moved to low-wage countries. And there is no money in working with the lower end of the service sector. It is among the high-end companies that the profitable customers are to be found. Normally such companies do not have problems with directly work-related ill health; they have problems with stress and other socio-psychological issues, which concern their employees' private lives as much as their working lives.

Hence, being successful in the profitable segment of the market is no longer about preventing ill health; it is about providing services that help employees to stay healthy and fit for work. It is typically said that high-end companies employ people who have to deal with a rapid tempo, high but imprecise expectations, an abundance of choices and opportunities, and potentially conflicting interests especially relating to the balance between private and professional life. As one psychologist explained:

... such employees confront various health risks that concern the difficulties of managing all parts of their lives. At times they suffer from stress: they are depressed because they do not spend enough time with their kids, sometimes they do not sleep well, and so on. But that is not the whole story: they are also part of a culture where the norm is that you should constantly try to improve, become healthier, and so on

The OHSs companies have responded to the needs of these customers by providing services that concern both dimensions touched upon in the last quotation: helping employees to steer free from health risks and to help them improve their health and well-being. The general term for such services is Worksite Health Promotion (WHP). One health coach defined WHP in the following way:

If our objective is to prevent ill-health, [then] we search for concrete health hazards in employees' immediate work-environment and give directives on how these can be handled. When, however, our objective is to promote employees' health and well-being, our perspective is much broader and we do not give directives, but try to help or coach employees to choose freely a healthier way of working and living. Hence, rather than saying that an employee should work and live in this or that particular way, we map the employee's work routines and lifestyle, trying to distinguish what is already good from what is not so good, and then we try to promote the former by providing the necessarily skills.

This view corresponds with what other studies have reported, where WHP is distinguished from traditional medical treatments by its ambition of being patient-centred in its approach and holistic in its mode of analysis. In the OHSs sector this has entailed a change in focus in the OHSs companies away from the work-environment to the private sphere of their clients' lives. A psychologist in one of the OHSs companies explained that this change of focus is somewhat problematic because, 
... the very definition of OHSs is to deal with work-related health issues. In reality, however, it is no longer what we do. I am not saying that our services do not concern work-related health issues. But mostly the distinction between work-related health and non-work-related health is very difficult to make. If, for example, one of my clients is stressed out and depressed, is this because he has a hectic job with a lot of responsibilities or is it because he has three children and his wife wants a divorce? In such a situation I obviously cannot leave the family situation aside, but nor can I truthfully say that the roots of the problem are work-related. But mostly this does not matter, because if the employee is important to his employer, the employer wants him back regardless if his basic problems are private or professional.

As the quotations above more or less explicitly state, the turn towards WHP implies a fundamental change of the OHSs sector. Whereas OHSs was defined by its concern with health issues that were work-related, in that the causes of ill health or some health risk were to be found at work, OHSs now increasingly concern health issues, which affect or may affect employees' work performance, but where the causes of potential or actual ill health are to be found in the private sphere or in the integration of the private and professional sphere of employees' lives. Hence, with the turn towards WHP the main task of the health professionals in the OHSs sector is to help companies make sure that their employees' whole life-situation is such that they are likely to remain not only healthy in a restricted bio-medical sense, but also healthy in the sense of being capable and efficient at work.

The fact that the OHSs sector has begun examining clients by using a much wider lens is also reflected in how the very notion of health is understood. As one health coach said: 'To us, health is no longer merely a question of whether or not our clients are defined as such in medical tests, it also relates to clients' lifestyles, if they are motivated, active, self-aware, and able to take care of their health.' Hence, health is increasingly seen to signify certain behavioural and personal characteristics. The active and motivated employee who seeks to improve himself or herself in all areas in life and who maintains a vigilant attitude towards his or her health and well-being is typically seen as healthy, whereas the employee who lacks drive, is negative, and seems unwilling or unable to care for his or her health is typically seen as representing the risky group of 'the potentially ill'. A physician pointed out that this new and more encompassing notion of health relates directly to a new culture and managerial philosophy in their customers' organizations:

I think the new type of health services that we provide relate to how health has become an integrated part of most of our customers' culture and philosophy. It is often assumed nowadays that a healthy company is an efficient company. Healthy individuals are seen to be more change prone, self-managing, and so on; so nowadays all companies want to take the 'health-turn'.

Hence, the turn towards WHP conveys a partly new notion of health that implies a particular lifestyle that is active, motivated, and self-aware. Furthermore, this new notion of health is not merely seen as a value in its own right, but it is also seen as a vital resource that makes employees more productive, flexible, and generally more appropriate for the type of work and careers that current working life can offer. 
The OHSs companies offer a range of services that may generally be given the label WHP - programmes for stress-management, for work-family life, for the improvement of one's body-mass index (BMI), and so on. Two examples illustrate the more concrete meaning and effects of such programmes. One is a programme for so-called lifestyle, health, and career coaching that many OHSs companies offer. Generally, employees attend this type of programme as a fringe benefit, a sign of that one is considered valuable by one's employer. An HR manager explained that,

\begin{abstract}
... these programmes are not for all employees. They are intended for those employees who are in the middle of their careers, who want to perform better at work, who want to be more challenged, more enthusiastic about work, and so on, but who find it difficult to combine those ambitions with the rest of their lives where they might have a family, a house with a garden, and all of those things.
\end{abstract}

Typically a lifestyle and career-coaching programme involves a series of three to five steps. The first step, as a health therapist described,

\begin{abstract}
$\ldots$ is to help the employee describe for him or herself how he or she lives on a day-to-day basis; what kind of work he or she is doing; whether or not he or she is happy with life in general; whether or not he or she is satisfied with his or her work and career; whether or not he or she is able to uphold a sound balance between work, family, and private life, and so on.
\end{abstract}

By asking and answering these questions the employee is meant to become aware of his or her life and career and can begin to think about whether or not he or she is on the right track. The second step is to establish a comprehensive 'self analysis', where the employee is asked first to describe his or her personal characteristics, then to describe what he or she believes what other people would say are his or her main personal characteristics, and finally to point out which of these characteristics are his or her strong qualities and which that are his or her weak qualities. On the basis of the two first steps, the employee is then, as a third step, given the task of working out his or her visions and goals, on the one hand, concerning his or her work, and, on the other hand, concerning the rest of his or her life. Once these steps are completed the health coach helps the employee to work out a concrete plan for how the career and life goals can be achieved. But this is not something that the health therapist does for his or her client:

\footnotetext{
... my role is that of a coach. I ask the questions and thereby direct the employees' attention in some directions instead of others. But it is the individual who comes up with the answers. It is so much more powerful to hear yourself say what you feel about yourself, your job, and so on, than to hear it from someone else.
}

In these mapping, analysing, and goal-setting activities, work and private life are treated as two separate spheres that should be managed using the same basic principles. A health therapist said that,

\footnotetext{
... while it is important to keep these spheres apart, it is also important to see how they interrelate. You cannot excel in your career if you do not consider how it affects your private life and vice versa. So in both spheres strategic problems need to be pinpointed and related to one another and goals have to be set which consider how the other sphere is affected.
} 
One health therapist who had recently coached a promising, up-and-coming manager in his mid-30s gave a concrete example of these activities. The manager had begun showing signs of stress, which, among other things, surfaced in the forms of a sleeping disorder and of irritated and aggressive behaviour that significantly affected the working climate among his subordinates. The therapist explained how the problem was clarified:

\begin{abstract}
In this case I helped him see how his professional life and his private life were two equally important domains, because until then everything had been about work. At first he did not admit that, but when we mapped out his daily routines, his interests, what he thought about, dreamt about, and so on, it became obvious that most of his days and nights were occupied with work.
\end{abstract}

The 'solution' that the health therapist worked out with this client was to treat his work and his family life as two separate enterprises. The health therapist went on:

... by treating his family as an enterprise of equal importance as the professional enterprise he was managing, he began to find it easier to balance work and private life. His wife, who is a housewife, was titled president of the family enterprise while he was president of the professional enterprise. So, now there were two managers and two enterprises.

In general the lifestyle, health, and career programme can be seen as expressions of how OHSs companies seek to exploit the growing concern among HR managers that employees who may have the proper formal competencies lack the necessary and required social and lifestyle skills (e.g., the capacity to adjust flexibly to changes in the work situation, to cope with stressful situations, to stay fit and healthy, etc.). As expressed by an HR manager in a large Swedish insurance company:

[C]ompanies have always searched for excellence when they hire and promote people. But today, the meaning of the word 'excellence' has much wider connotations. It is no longer just a statement about the particular set of occupational skills that a person may hold. Now, excellence is also used to characterize a person who leads a particular type of life, who is physically active, who eats proper food, who avoids unnecessary risks, who is moderate with drugs and alcohol, and so on.

In this context the lifestyle, health and career programme is supposed at once to help companies monitor the potential of their human resources and to help employees help themselves to become healthier, happier, and in that process to be better able to match the expectations of their employers.

The other example is about another type of WHP programme that many OHSs companies offer, the stress-management programme. With respect to the issues the stress programme seeks to cover, its focus is narrower than the lifestyle, health, and career programme. Furthermore, in contrast to the former programme it is intended for employees who have shown early signs of ill health caused by stress. Yet these programmes are still basically similar in that they examine and correct not primarily the organization of work but the lifestyle and the individual self. In the case of the stress programme the objective is to teach individuals how to handle stress, or rather the early signs 
of stress, by giving them better 'self-knowledge' and abilities to maintain 'a dialogue with themselves'. Yet, as a therapist explained, 'it all has to start with the clients' accepting that they are responsible for their lives, that they are not victims, and that they always have a choice'. The therapist related how many clients,

... initially tend to place their stress-problems outside themselves. It is their job that is too demanding, or their boss who expects too much or is unable to set realistic and clear goals and performance standards. We try to turn that around. We want them to see that the problem and the solution lie within themselves.

Thus, the stress-management programme emphasizes the idea of individual responsibility. One therapist explained that the focus on individual responsibility does not imply that the OHSs companies would consider the employees' work conditions as unproblematic with regard to stress. Quite the contrary, but

... the possibilities of changing work conditions are generally very limited. We can help by temporarily limiting the responsibilities and the performance criteria of those employees who come to us with stress problems. Yet in the long run the employees either learn to cope with their work or try to find other less demanding work.

In this respect, the OHSs basically treat the clients' professional environment as something that is accepted. Although it profoundly affects the clients' health and well-being, the clients cannot do much about it other than learning to cope with. A therapist discussed this point:

[U]ltimately we do try to teach them how to cope with their work and life,. We teach them to listen to themselves, to choose, and to accept the fact that in the final instance it is they themselves who are responsible for their health and well-being. If the result of the stress programme is that a client decides to leave [his or her] work for some other career, so be it.

Therefore, in the stress-management programme the focus of the therapeutic sessions is the individual and the aim is to teach the individual how to adapt to work rather than the other way round. Differently put, the problem, or at least the part of the problem, that the therapist seeks to do something about is on the individual level, not on the organizational level; it is the individuals' lack of ability to cope with stress, to set limits, and to prioritize that is at the centre of the therapists' attention. In this pursuit the first step in the therapy is to establish a trustful climate that helps the employee to accept and commit to 'the fact' that is he or she himself or herself who has a problem with stress. A therapist said that,

... daring to be open and honest about the fact that you do have a problem is very important, because stress has a lot to do with an experience of not being able to meet expectations, not the least those expectations that you have on yourself. Declaring openly that you have a problem relieves you of some of that burden, at least momentarily, and gives you the opportunity to be honest to yourself and to accept that you have a problem.

In the long run, however, the therapist emphasized that it is obviously not enough for the employee just to be open and honest about his or her problems 
to the therapist and to himself or herself. The employee also needs to be open to his or her colleagues and supervisors. 'We try', the therapist continued, 'to involve employees' superiors in the therapy after some sessions, because if there is no understanding and acceptance for an individual employees' problems, the risk is that things will be just like they were before the problems surfaced'.

The second step in the therapy revolves around the mapping out of the employee's daily routines. These mapping procedures concern not only how the employee handles his or her work, but also the rest of the employees' daily routines. As one psychologist mentioned:

Many companies talk about 'the 24-hour employee' these days. It means that they take an interest in and care for their employees not only at work, but also in their lives outside work. This is not merely a question of being nice and caring. Managers know that the ways in which employees live outside work significantly affect their abilities and their efficiency at work.

Clients are taught to deal with stress not only by being more aware and reflective about their own behaviour and attitudes, but also by beginning to think strategically about all areas of their lives. More specifically, clients are taught to make distinctions between work, private life, and self, and to set goals in all three areas. One therapist said that,

... it is a mindset that we want our clients to adopt. They should be aware of what they are doing and they should think in relation to how the different areas of life, work, private life, and self relate to another.

Some interviewees considered the stress-management programme to be somewhat problematic since it could jeopardize the career prospects of the employee. For instance, a therapist said that,

... the problem when trying to deal with stress is that the capability to work under pressure and to cope with stress and uncertainty are core features in contemporary descriptions of successful career persons. To declare openly, perhaps even in front of your boss, that you cannot cope with the stress will be seen by many as a way of saying that you are no longer in the race.

An employee who had undergone therapy for a couple of months because of problems with stress commented on this issue:

At some point I had to admit, not the least to myself that I had a problem. I received therapy and I was helped by the therapist to discuss with my boss how my work could be changed so that it would be less stressful. For me, this was necessary, but the price I had to pay was relatively high, because now no one sees me as a person with much chance of advancing career-wise.

Another employee who had also gone to therapy for her stress problems likewise elaborated on this point:

About a year ago I was on the verge of crossing a line where things would have begun to fall apart. It was actually my boss who acknowledged the state I was in and suggested that I should seek help. To step aside for a while and to receive therapy proved to be both 
necessary and helpful. It helped me to look at myself, my work, and my life with some perspective. Before I was completely occupied by my work, now I am able to keep some distance. Yet at times I still feel a little bit bitter because throughout the whole process we never discussed how the organization in which I work could or should be changed. It was I who had a problem, it was within me and in the ways I related to and handled my work that the problems were to be found.

With regard to the WHP programmes accounted for above as well as to others offered, the interviewees generally emphasized that participation is voluntary and that active and motivated participation is required for any of the WHP programmes to have any positive and lasting effect. One HR manager pointed out that 'whereas the employees have a direct right to demand that their employers see to it that the work environment is safe, the employers cannot command their employees to eat properly, to exercise, and so on'. In that connection a health-promotion specialist said that 'we can provide our clients with the necessary knowledge and skills, and inform them about the responsibility they have to keep themselves in shape, but we cannot obviously demand that they actually do what we advise them and want them to do'. Yet some of the OHSs professionals underlined that there are delicate issues involved here: 'Even though it may not be spelled out, nowadays companies tend to employ people not only because they have certain formal competencies, but also because they are fit, healthy, and perhaps even because they look good.' In that connection, some OHSs professionals stressed that 'if you never read anything, just sit around watching TV, eating fast-food and never exercising, you might end up as a very unattractive employee'. These quotations indicate that although the employers have no right to command employees to live in a certain way so that they remain not only healthy but also attractive and capable employees, this was still expected, especially from employees with career ambitions. An HR manager believed that this expectation is further reinforced by the fact that 'many companies have begun to focus on health issues in the recruitment processes and in the yearly development talk that all employees have with their superiors'.

In addition to this normative pressure there is also a potential coercive pressure on employees to take part in and to follow the WHP programmes provided by the OHSs companies when an employee is unable to cope with work because of his or her health. As one nurse noted: 'if someone cannot cope for instance with stress and is relieved from work because of illness, this person is obliged to follow the therapeutic procedures and the directives outlined by the responsible medical professional'. In general, this relates to what Parsons (1951) has referred to as 'the sick role', in which a person who is diagnosed as sick or injured has a right to care and is relieved of his or her ordinary responsibilities - say, those concerning work - provided that the person subordinates himself or herself to the authority of medical expertise. What this means is that when an employee has been diagnosed as ill because of his or her incapability to work, the OHSs professionals have considerable power to influence all spheres and parts of the employees' life. Furthermore, the employee has considerable incentive to follow the directives of the occupational health-care specialists since limited health improvements or limited motivation and activity in trying to become better can be interpreted as a sign that the employee is inappropriate for his or her job and should seek other assignments. 
It is important to note here is that those employees who fail to adjust their lifestyles and their selves to the combined conditions of work and life tend to be diagnosed as suffering from ill health, for example, in the form of stress and sleeping disorders. A former key account manager in a bank related a personal story on this matter,

\begin{abstract}
When I began working here I was very ambitious and my bosses gave me loads of work. I never said no, and I could not, really, because, I mean, you are not supposed to say no; it is sort of expected that new employees who are relatively fresh from university should be prepared to work hard and long hours. Yet after two years or so I started getting stress problems - at times I could not sleep and I became emotionally unstable. I did receive help from a therapist, but I still remained unable and unwilling to put in those long and demanding hours. My therapist eventually advised me to seek another job because of health reasons, and I did. But I think it is sick that I should be considered ill because I cannot cope with a job where it is expected that you work enthusiastically up to 12 hours a day.
\end{abstract}

\title{
Discussion and conclusions
}

Before we discuss the more specific implications of the turn to health promotion in OHSs, let us briefly return to the role of these services within the context of the broader transformation from Fordism to post-Fordism. I have outlined how Fordism was based on a subtle alliance between a massproducing-factory regime and a welfare regime and how experts in medicine, psychiatry, economy, pedagogy, and so on, were central in in maintaining this alliance. On the basis of the authority of these professions, a combination of regulatory arrangements, such as collective social insurance and unemployment support, and disciplinary arrangements, such as public schools, health and child care, was set up, which managed to reconcile the interests of big capital with those of big labour by providing appropriately configured workers and consumers to the former and social and economic security to the latter. Yet I have also outlined how the new form of capitalism that was shaped in the aftermath of the economic crises of the 1970s needed both fewer and a different breed of workers, thus undermining the legitimacy of the welfare state and opened for neo-liberal reform programmes.

It is in the context of the neo-liberalization of the welfare state that a discussion about the transformation of Swedish OHSs must begin. As stated in the introduction of the case study, countries differ with regard to the more specific ways they organize and finance OHSs. Yet, as part of a general neoliberalization, there is a trend in all former welfare states either to privatize or to set up pseudo-markets for OHSs (e.g., SOU, 2011: 79). According to advocates of neo-liberalism, this kind of privatization of social welfare simultaneously reduces taxes while creating new markets for capitalist expansion. In addition it is claimed that these changes make society more liberal because privatization means that the state's monopoly of power over the usage of expertise is broken when it is offered through the 'free' market.

Yet neo-liberalism has never been intended to be a return to classical liberalism's emphasis on laissez-fair, but rather as a new form of state governance, which operates indirectly through expertise mediated via the play of market forces and individual choice (Foucault, 2007; Dean, 1999). In this 
regard, the case study presented in this article provides an example, giving us some clues of how health expertise is central in fostering a new working population that is not merely clinically healthy and physically fit, but also equipped with the right 'mindset' that makes it willing and able to handle the 'individualized risk management' associated with post-Fordism (Rose, 1993; Du Gay, 1996; Hancock \& Tyler, 2004).

More specifically, the case illustrates how the privatization of OHSs sets in motion a transformation of the role of OHSs experts. The purpose of OHSs is no longer merely to prevent work-related accidents and illness among all employees, but to coach and empower in particular core employees of business firms in how to make sensible choices with regard to their health, careers, families, and so on (Du Gay, 1996). Accordingly, this transformation is illustrative of a general trend among experts in mental and physical health of turning away from a traditional hierarchic practice, where the client or patient is subordinated to the experts' authority and given instructions that he or she is expected to obey, to a collaborative practice where the client is instead offered expertise as a form of service and support that the client then either chooses to follow or not (Lupton, 1995). As Rose (2007) has noted, rather than regulating individuals by implanting norms of good conduct, these ways of using expertise appeal to individuals' will to improve themselves and to use the expertise offered as a means of doing so.

Using Foucault's terminology (Foucault, 2007), we can say that the turn to market-distributed expertise in OHSs has led to a disciplinary logic of power that has been replaced, or at least complemented, by a 'pastoral logic of power'. Whereas 'disciplinary power' is based on the knowledge that comes from the examinations of an individual by an authority, pastoral power is based on the knowledge that comes from the individual, because he or she avows or confesses to an authority what she or he feels is good, bad, problematic, and so on. Under the guidance of a moral authority, be it a therapist, a pastor, a coach, a mentor, and more, pastoral power binds the individual to the objectified image of the self that the individual himself or herself has avowed (Barrat, 2002; Covaleski et al., 1998). As we saw in the accounts above, it is through pastoral forms of power and expertise that active individuals are now to be socialized; individuals who are not subjugated to the rules of experts, but who make active use of expertise to learn to define and govern themselves and to receive moral guidance on how they should improve themselves in response to the opportunities and risks they face.

Central in this pursuit is a partly new or expanded notion of health. For as we saw, health was seen to include not only individuals' bio-medical condition, but also their attitude, motivation, level of activity, and so on, or more generally, their personality and lifestyle. This is in no way specific to the OHSs, but it is illustrative of a general trend expressed, for instance, by the definition of health set by the World Health Organization (WHO): 'Health is a state of complete physical, mental and social well-being and not merely the absence of disease or infirmity' (1948). To be considered healthy, then, you need to be positive, if not happy, and have an active lifestyle (Lupton, 1995).

Accordingly, we have seen how the WHP programmes offered to employees made health, well-being, and prosperous careers products of individuals' lifestyles and personalities. Through the health experts' advice and support individuals are provided with knowledge of how they can sleep better, balance 
private and professional life better, eat better, and so on. Yet we have also seen that more important than providing individuals with 'proper' knowledge was making them accept that they themselves are responsible for their health and making sure that they have enough 'self-discipline', 'motivation', and 'selfcontrol' to shoulder this responsibility.

Two general consequences seem to follow from these observations. First, WHP programmes contribute to nurturing ascetic personal qualities and an ethic which makes all spheres of life subject to managerial practices. On several occasions we have seen how health expertise attempted to teach their clients to attend to their lives and selves strategically (i.e., through the controlled use of specific means to achieve specific ends). To achieve health and even happiness, it seems, individuals 'ought' to set goals and standards and 'ought' to strive to improve. Secondly, WHP programmes present themselves as opportunities for those who have the healthy character traits to mark their distance from and moral superiority over those who lack them. This elitist tendency is in fact implied by the very name of 'Worksite Health Promotion'. This title suggests that the purpose of WHP programmes is not to create self-discipline, motivation, self-control, and so on, that is, the moral faculties that are seen by OHSs specialists as the foundation of health, but rather to promote these traits and to guard against the threats that may result in individuals losing them. In this respect the WHP programmes do not seem to be conduits to better health, well-being and success that are equally available to everyone. On the contrary, for those who lack the 'moral faculties' required for a healthy life and a prosperous career, WHP programmes instead come across as tests that aim to reveal precisely those deficiencies. Therefore, whereas WHP programmes provide employees with opportunities to assert their moral superiority over those who are incapable of taking advantage of these opportunities, they provide employers with the possibilities to 'blame the victim' legitimately because they can say 'you have yourself to blame; you have been given all these opportunities (i.e., WHP programmes) but you have not had the character to get anything out of them'.

These findings can be related to studies of 'the active' or 'neo-liberal' society that have shown that large parts of the populations have been unable to embrace an active subjectivity fully (e.g., Dean, 1995; O'Malley, 1992). These studies argue that a growing number of people are systematically dislocated and dispossessed by the impact of advancing market relations and dismantled social-security nets. In this respect there are signs that neo-liberalization in post-Fordist societies produces paradoxical results: while it promises freedom of choice, activity, and inclusion for everyone, it tends to create a large number of individuals who are excluded from society's front stages. The WHP programmes offered to employees appear to play an interesting role in this regard, for they tend to operate as catalysts in processes where social class is turned into a question of health. When, as we have seen above, health is treated as a product of individuals' choice of lifestyle, the healthy individual is also the 'good', 'responsible', and, in general terms, the 'morally superior' individual.

Furthermore, health appears to become part of a more encompassing new version of the Protestant work ethic, which declared that the 'good and moral man' to be hard-working and disciplined, and the immoral man idle, undisciplined, and non-working. As Baumann (1998) points out, this work ethic and the way it was preached in schools, families, churches, and so on, played 
an important role in industrial societies of the late nineteenth and early twentieth centuries, for it helped to push people into the factories and once they were there it made them accept their low wages and poor working conditions with little complaint. In current post-Fordist working life, where the 'good employee' is no longer the obedient, disciplined servant, but the active and entrepreneurial employee who is capable of disciplining himself or herself, the experts of health have become the new pastors, preaching the secular ideology of self-improvement as a means to well-being and professional success. As Boltanski and Chiapello (2005) has shown, the ethic that these new pastors preach is not simply the Protestant ethic of toil and of rationalinstrumental conduct that Weber so famously described as the spirit of nineteenth- and twentieth-century industrial capitalism . Rather, it is an ethic which puts a premium on activity 'without any clear distinction between personal or even leisure activity and professional activity. The doing something, to move, to change - this is what enjoys prestige, as against stability, which is often regarded as synonymous with inaction' (Boltanski \& Chiapello, 2005: 155).

Should we then conclude that this new work ethic, backed as it is by the scientific discourse of health, gives rise to an increasingly harsh distinction between the morally superior and the morally inferior? The studies of Bourdieu (1999), Baumann (1998), and Waquant (2003) have proposed that this is the case; they argue that western post-Fordist societies have given rise to an 'underclass' of individuals who are not merely useless, unhealthy, and morally inferior with regard to the standards of the labour market, but who are also potentially dangerous with regard to the norms of citizenship. According to these authors, the role of the neo-liberal state is less and less about trying to help these individuals, and more and more about protecting the rest of the population from them by means of a stronger penal system.

This study also points to a related potential development, where medical language and expertise mask moral judgements. As we have noted in the account above, those individuals who fail to live according to the norms and ideals of being active do not seem to be deemed to be morally inferior, but are instead considered to be 'ill' or 'potentially ill'. Somewhat paradoxically, the tendency of regarding health not merely as a clinical condition but also as a matter of choice and behaviour seems to open the possibility of seeing the failure or lack of motivation to take care of oneself as a sign of a defect or illness. This study thus suggests that individuals who fail to meet the performance standards of contemporary working life are 'medicalized' (Zola, 1972). 'Medicalization' then refers to the tendency that more and more of everyday life and behaviours fall under the dominion of medical expertise and medical diagnosis. Examples abound: compulsive gambling, substance abuse, eating disorders, stress disorders, sexual addiction, learning disabilities, procrastination disorders, and more. This labelling of groups of individuals as sick or disabled because they have failed to take care of themselves in accordance with norms and ideals of health, well-being, employability, and so on is a way of leading them into the classical Parsonian sick role (1951), where they are relieved of their moral responsibility and thus from their failure provided that they subordinate both to the authority of medical expertise and to the public authorities that make administrative decisions on the basis of medical diagnoses (Holmqvist \& Maravelias, 2011). Therefore, 'medicalization' (Zola, 1972) emerges simultaneously as a way of removing if the not the shame, then at least the blame of those who fail to be active, to take 
responsibility for their health and employability, and as a way of opening possibilities to rule these individuals through the authority of medical expertise.

\section{Acknowledgements}

I would like to thank the two reviewers and the editors of the NJSR, in particular Steven Connolley, for their thoughtful and constructive critique of the first version of this article.

\section{References}

Aglietta, M. (1979). A Theory of Capitalist Regulation: The US Experience. London: Verso

Arrighi, G. (1994). The Long $20^{\text {th }}$ century - Money, Power, and the Origins of our Time. London: Verso.

Barrat, E. (2002). Foucault, Foucauldianism and Human Resource Management, Personnel Review, 31(2), 189-204.

Baumann, Z. (1998). Work, Consumerism and the New Poor. Buckingham: Open University Press.

Boltanski, L. \& Chiapello, E. (2005). The New Spirit of Capitalism. London: Verso.

Bourdieu, P. (1999). Firing Back: Against the Tyranny of the Market. London: Verso.

Covaleski, M., Mark, W., Heian, J. B., \& Samuel, S. (1998). The Calculated and the Avowed: Techniques of Discipline and Struggles over Identity in Big Six Public Accounting Firms, Administrative Science Quarterly, 43(2), 293-327.

Crawford, R. (2006). Health as a Meaningful Social Practice: An Interdisciplinary Journal for the Social Study of Health, Illness and Medicine, 10(4), 401-420.

Dean, M. (1995). Governing the Unemployed Self in an Active Society. Economy and Society, 24(4), 559-583.

Dean, M. (1999). Governmentality: Power and Rule in Modern Society. London: Sage.

Dean, M. (2007). Governing Societies: Political Perspectives on Domestic and International Rule. New York: Open University Press.

Donzelot, J. (1991). The mobilization of society, in Burchell, G., Gordon, C., Miller, P. (eds.) The Foucault Effect, Studies in Governmentality. Chicago: The University of Chicago Press.

Du Gay, P. (1996). Consumption and Identity at Work. London: Sage.

Foucault, M. (2007). Security, Territory, Population: Lectures at Collège de France 1977-1978. Basingstoke: Palgrave.

Gramsci, A. (1996). Selection from The Prison Note Books. New York: Columbia University Press.

Greco, M. (1993). Psychosomatic Subjects and "the Duty to do Well": Personal Agency within Medical Rationality. Economy and Society, 22(3), 357-372.

Hancock, P. \& Tyler, M. (2004). MOT Your Life: Critical Management Studies and the Management of Everyday Life. Human Relations, 57(5), 619-645. 
Harvey, D. (1991). The Condition of Postmodernity. Cambridge: Blackwell publishers

Harvey, D. (2006). The Limits to Capital. London: Verso.

Holmqvist, M. \& Maravelias, C. (2011). Managing Healthy Organizations: Worksite Health Promotion and the new Self-Management Paradigm. London: Routledge.

International Labour Organization, ILO. (1985). Convention 161. Occupational Health Services Convention. Retrieved June 12, 2012, from http://www.ilo.org/ilolex/cgilex/convde.pl?C161

Lupton, D. (1995). The imperative of health, public health and the regulated body. London: Sage.

Myrdal, A, \& Myrdal, G. (1997). Kris i befolkningsfrågan [Crisis of the population question]. Stockholm: Albert Bonniers förlag.

O Malley, P. (1992). Risk, Power and Crime Prevention. Economy \& Society 21(3), 252-275.

Parsons, T. (1951). The Social System. New York: The Free Press.

Rose, N. (1993). Government, Authority and Expertise in Advanced Liberalism. Economy \& Society, 22(3), 283-299.

Rose, N. (2007). The Politics of Life Itself, Biomedicine, Power, and Subjectivity in the Twenty-First Century. Princeton: Princeton University Press.

Smith, V. (1997). New Forms of Work Organization. Annual Review of Sociology, 27,315-339.

Statens offentliga utredningar (SOU) (2004). Utveckling av god företagshälsovård [Development of good occupational health services] (2004:113). Stockholm: Fritzes

Statens offentliga utredningar (SOU) (2011). Kunskapsområdet företagshälsovård, en rapport om utbildning, utveckling och forskning [The competency of occupational health services, a report on education, development, and research] (2011:79). Stockholm: Fritzes

Vallas, S. (1999). Rethinking Post-Fordism: The Meaning of Workplace Flexibility. Sociological Theory, 17(1), 68-101.

Wacquant, L. (2003). Prisons of Poverty. Minneapolis: University of Minnesota Press.

Weber, M. (2001). The Protestant Ethic and the Spirit of Capitalism, London: Routledge.

Whyte, H. (2002). The Organization Man. Philadelphia: University of Pennsylvania Press.

World Health Organization, WHO. (1948). Preamble to the Constitution of the World Health Organization as adopted by the International Health Conference, New York, 19-22 June, 1946. Retrieved on June 12, 2012: http://www.who.int/about/definition/en/print.html

Zola, I. (1993). Self, identity and the naming question: Reflections on the language of disability. Social Science and Medicine. 36(2), 167-173. 